\title{
Determinação da exposição à chuva dirigida em Florianópolis, SC: índices de chuva dirigida e métodos semi- empíricos
}

\author{
Determination of exposure to driving rain in \\ Florianópolis, Santa Catarina: driving rain indices and \\ semi-empirical methods
}

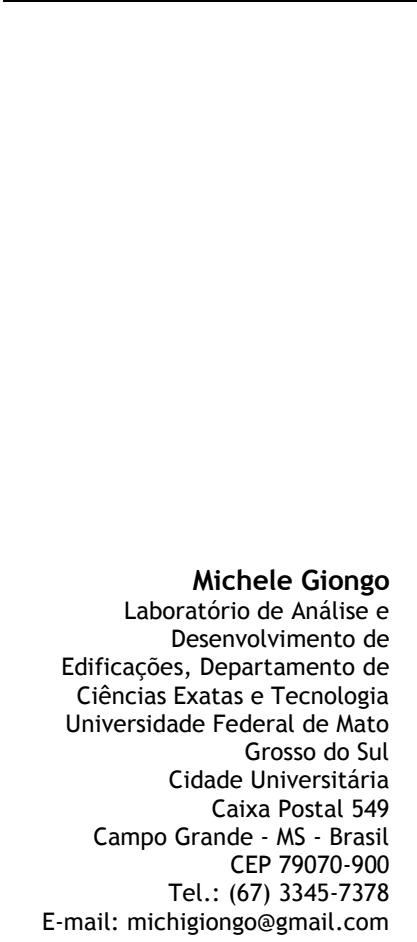

Ivo José Padaratz Programa de Pós-Graduação em Engenharia Civil Universidade Federal de Santa Catarina Caixa Postal 476 Florianópolis - SC - Brasil CEP $88040-900$

Tel.: (48) 3721-5177 E-mail: padaratz@gmail.com

Roberto Lamberts Programa de Pós-Graduação em Engenharia Civil Universidade Federal de Santa Tel.: (48) 3721-7090 E-mail: lamberts@ecv.ufsc.br

Recebido em 26/04/2010 Aceito em 25/12/2010

\section{Michele Giongo \\ Ivo José Padaratz \\ Roberto Lamberts}

\section{Resumo}

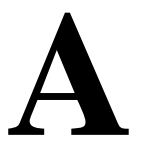

chuva dirigida, chuva carregada pelo vento que possui uma componente horizontal dada pela velocidade do vento, é a maior fonte de umidade que afeta a durabilidade e o desempenho higrotérmico das fachadas das edificações. Este trabalho apresenta uma avaliação do nível de exposição das edificações à chuva dirigida em Florianópolis-SC com o auxílio de índices de chuva dirigida e de índices de chuva dirigida em parede vertical. Para a obtenção desses parâmetros aplicaram-se fórmulas empíricas já existentes na literatura internacional e utilizaram-se dados de velocidade e direção do vento e de precipitação de estações meteorológicas localizadas na Ilha de Santa Catarina e na cidade vizinha de São José. Foram feitas análises para três períodos distintos: (a) 1961-1970, (b) 1991/1993-1996 e (c) setembro de 2005 a agosto de 2006. De acordo com os resultados, a exposição da área de estudo variou de local protegido a exposição alta, sendo as direções sudeste, sul e sudoeste as mais críticas quanto à exposição das fachadas à chuva dirigida. $\mathrm{O}$ trabalho traz informações úteis para os projetistas, no intuito de criar projetos mais adequados à proteção das fachadas das edificações na área de estudo, além de trazer contribuições para as áreas de estudo de durabilidade e conforto térmico das edificações.

Palavras-chaves: Chuva dirigida. Índice de chuva dirigida. Fachada. Edificação. Durabilidade. Conforto.

\section{Abstract}

Driving rain, the rain carried by the wind with a horizontal wind speed component, is a major humidity source affecting the durability and hygrothermal performance of building façades. The article presents an assessment of driving rain exposure level in Florianópolis-SC, using driving rain indices and driving rain wall indices. In order to obtain these indices, semi-empirical formulas from the international literature on driving rain as well as wind speed, wind direction and rainfall data from meteorological stations in Santa Catarina Island and the neighboring city of São José were applied. The analysis covered three periods: (a) 1961-1970, (b) 1991, 1993-1996, and (c) from September 2005 to August 2006. The analysis revealed that the exposure level of the area investigated varied from moderate to high, with the southeast, south and southwest being the most critical directions for driving rain exposure. The results of this investigation provided information that is useful for the design of building façades within that area and may contribute to increase the knowledge on durability and thermal comfort.

Keywords: Driving rain. Driving rain index. Façade. Building. Durability. Thermal comfort. 


\section{Introdução}

Chuva dirigida é a chuva carregada pelo vento que é lançada de encontro ao envelope da edificação (VAN MOOK, 2002) e que possui um ângulo característico quanto a um plano vertical (KARAGIOSIS; HADJISOPHOCLEOUS; CAO, 1997). Pode ainda ser definida como a quantidade de chuva que passa através de uma superfície vertical (STRAUBE; BURNETT, 1997) com uma componente da velocidade do vento (BLOCKEN; CARMELIET, 2004).

O estudo da chuva dirigida é importante para muitas áreas de pesquisa, tais como as ciências da terra, a hidrologia, a meteorologia e a ciência da construção. Para as edificações, a chuva dirigida é uma grande fonte de umidade que afeta o desempenho higrotérmico e a durabilidade das fachadas. Os danos causados pela água da chuva vão desde problemas de efeitos estéticos até degradações profundas (CIRIA, 1992). Entre esses danos estão infiltrações, eflorescências, bolores, goteiras, manchas e degradação dos materiais que constituem os componentes das fachadas.

Segundo Choi (1999), os danos causados aos edifícios pela água da chuva e os prejuízos financeiros decorrentes desses danos podem ser atribuídos a dois tipos de mecanismos: um se refere à entrada da água de chuva através das fachadas para o ambiente interior, é um processo, em geral, de curta duração, e a degradação depende da intensidade da chuva dirigida; o outro se refere à entrada de umidade nos materiais da envoltória do edifício, é um processo de longo prazo, e a degradação depende da quantidade de chuva acumulada em determinado período. De acordo com Blocken, Hens e Carmeliet (2002), o escorrimento da chuva sobre a fachada é um terceiro processo que acarreta degradação da fachada decorrente da chuva dirigida.

O acúmulo de água da chuva nas paredes externas da edificação também pode provocar a diminuição da resistência térmica dos materiais que compõem essas paredes, tornando-as mais permeáveis ao calor. Por essa razão, os dados de chuva dirigida são importantes para os estudos de problemas relacionados ao fluxo de calor nas edificações e ao consumo de energia para atingir o conforto térmico em ambientes internos (CHAND; BHARGAVA, 2002).

Os problemas relacionados à chuva dirigida trazem muitos inconvenientes e são motivo de desconforto e desagrado ao usuário, sendo responsáveis por grande parte dos problemas de umidade. Um estudo realizado no IPT em edificações habitacionais (casas térreas e apartamentos) verificou que a maior parte das manifestações de umidade observadas foi devido à infiltração, independentemente da idade da construção (IOSHIMOTO, 1988). Segundo Perez (1988), estudos realizados no IPT e em institutos de pesquisas de outros países mostram que, entre os problemas de umidade, as infiltrações aparecem com uma frequência de $60 \%$ a $70 \%$ e se originam principalmente nas fachadas (janelas, portas e paredes).

A estanqueidade à água da chuva é um dos parâmetros de desempenho de uma edificação. Segundo a NBR 15275-4 (ABNT, 2009), todos os componentes das fachadas de um edifício, como paredes, painéis e esquadrias, bem como a junção entre as esquadrias e a parede devem ser estanques à água da chuva incidente ou a outras fontes, não apresentando infiltrações que proporcionem escorrimentos, borrifamentos ou formação de gotas aderentes na face interna da fachada. Dessa forma todos os componentes devem ser projetados e construídos de maneira a impedir a penetração de água da chuva incidente. Segundo Mustelier (2002), a chuva incidente é a precipitação combinada com vento que aumenta a pressão atmosférica no exterior do edifício e que, assim, provoca infiltração de água até mesmo por pequenos orifícios e fissuras da vedação externa.

Apesar de sua importância para diversas áreas do conhecimento, como é o caso da construção civil, o estudo da chuva dirigida ainda é novo no Brasil, com poucos estudos publicados. Um dos fatores que dificultam esse estudo é a pouca disponibilidade de dados adequados.

Tendo isso em vista, o presente trabalho apresenta um estudo da exposição de edificações à chuva dirigida para Florianópolis-SC a partir da análise de dados meteorológicos e da aplicação de fórmulas semiempíricas existentes na literatura internacional para determinar a exposição global e a exposição de fachadas de acordo com a respectiva orientação. Este estudo apresenta ainda um método de uniformização dos dados meteorológicos para a aplicação dessas fórmulas e possibilita a comparação do resultado global com o mapa brasileiro de chuva dirigida montado por Lima e Morelli (2005).

\section{Revisão bibliográfica}

A quantidade de chuva dirigida que incide nas fachadas é influenciada por diversos parâmetros, como a geometria do edifício, a topografia, a posição das fachadas, a velocidade e a direção do vento, a intensidade da precipitação, o tamanho 
das gotas e a duração do evento de chuva (BLOCKEN; HENS; CARMELIET, 2002). Esse grande número de parâmetros e suas variações fazem com que a quantificação da chuva dirigida seja um problema complexo.

$\mathrm{O}$ ângulo com o qual a chuva atinge uma parede vertical depende da combinação da velocidade do vento com o tamanho das gotas de chuva. Já a entrada de umidade na edificação depende da capacidade da fachada de absorver umidade, de falhas em juntas de elementos de mesmo material e de falhas de juntas de materiais diferentes, além do grau de exposição ao qual o edifício está submetido (MARSH, 1977).

De acordo com Blocken e Carmeliet (2004), o estudo da chuva dirigida na ciência da construção está dividido em quantificação das cargas de chuva dirigida e estudo da resposta dos edifícios a essas cargas, sendo três os métodos utilizados para esse tipo de estudo: métodos experimentais, métodos semiempíricos e métodos numéricos.

Em 1955, Hoppestad apresentou duas relações nas quais se baseia a grande maioria dos métodos semiempíricos existentes: o índice de chuva dirigida (ICD) (Driving Rain Index - DRI) e a relação de chuva dirigida (Driving Rain Relationship) (BLOCKEN; CARMELIET, 2004). Durante os anos 60, o CIB (Conseil International $d u$ Bátiment) estabeleceu o ICD como sendo o produto da quantidade de precipitação pela velocidade do vento (PEREZ, 1988). Esse índice pode ser obtido pela Equação 1 (LACY, 1977; SABATTINI, 1988; SILVA; GIRALT, 1995):

$$
I C D=V \cdot \frac{P}{1000}
$$

Onde:

$I C D=$ índice de chuva dirigida $\left(\mathrm{m}^{2} / \mathrm{s}\right) ;$

$V=$ velocidade média anual do vento $(\mathrm{m} / \mathrm{s}$, medida a $10 \mathrm{~m}$ de altura); e

$P=$ total de precipitação anual (mm).

Quando o ICD é calculado a partir das médias anuais de vento e precipitação acumulada anual média, ele é denominado ICD anual. Pode-se também calcular o índice de chuva dirigida para cada orientação de vento e criar rosetas de ICD direcional para determinada localidade. Esse índice direcional facilita a visualização e a análise da influência de cada direção quanto à exposição à chuva dirigida. Pode-se ainda calcular índices mensais para se fazer uma comparação do comportamento da chuva dirigida durante o ano.

Segundo Lacy (1977), o ICD anual é um método razoavelmente preciso de comparação do total acumulado de chuva dirigida em paredes de lugares diferentes e dá ao projetista a possibilidade de comparar a exposição de um lugar com outro que lhe é familiar.

O ICD é citado por alguns documentos como critério de avaliação da exposição das edificações ao meio no qual estão inseridas. Entre eles estão Lacy (1972), o BS Code of Practice CP121: Part 1 - Brick and block masonry (MARSH, 1977) e a BS 5262 (BSI, 1976). Lacy (1972) cita o ICD como critério útil para problemas relacionados à exposição das edificações à chuva em nível de planejamento regional e para alguns casos de problemas relacionados à degradação devida à absorção de água pelos materiais constituintes da fachada em nível de projeto.

Com base em índices de chuva dirigida anuais, Lacy e Shellard (1962) apresentaram mapas de exposição à chuva dirigida para o Reino Unido. Lacy $^{1}$ (apud FAZIO; MALLIDI; ZHU, 1995) adotou três faixas de exposição à chuva dirigida de acordo com o ICD anual obtido:
(a) local protegido para $\mathrm{ICD} \leq 3$;
(b) exposição moderada para $3<\mathrm{ICD} \leq 7$; e
(c) exposição severa para IDC $>7$.

Com base nessa metodologia, pesquisadores estabeleceram o ICD para muitos lugares do mundo, e diversos países tiveram mapas de chuva dirigida confeccionados, como Suécia, Dinamarca, Canadá, Estados Unidos e China (FAZIO; MALLIDI; ZHU, 1995). No Brasil, Silva e Giralt (1995) estabeleceram o ICD para a cidade de Porto Alegre a partir de dados horários de precipitação, velocidade e direção do vento de cinco anos (19771981), encontrando o valor de 3,92, exposição moderada.

Esses graus de exposição podem precisar de ajustes, de acordo com as condições locais, como proximidade da costa, elevação do terreno e altura da edificação. Algumas regras são recomendadas (MARSH, 1977): para áreas onde o ICD calculado é menor que $3 \mathrm{~m}^{2} / \mathrm{s}$ e que estão distantes até $8 \mathrm{~km}$ do mar ou grandes estuários, a exposição deve ser tida como moderada; áreas com ICD maior ou igual a $5 \mathrm{~m}^{2} / \mathrm{s}$ e menor que $7 \mathrm{~m}^{2} / \mathrm{s}$ e distantes até 8 $\mathrm{km}$ do mar ou grandes estuários devem ser classificadas como área de exposição severa.

Chand e Bhargava (2002) adotaram uma quarta faixa, além das três apresentadas por $\operatorname{Lacy}^{2}$ (apud FAZIO; MALLIDI; ZHU, 1995), na confecção de

${ }^{1}$ LACY, R. E. Driving Rain Maps and the Onslaught of Rain on Buildings. In: RILEM/CIB SYMPOSIUM ON MOISTURE PROBLEMS IN BUILDINGS, Helsinki, 1965. Proceedings... Helsinki, 1965.

${ }^{2}$ Idem. 
um mapa de chuva dirigida para a Índia, subdividindo a terceira da seguinte forma:

(a) exposição alta para $7<\mathrm{ICD} \leq 11$; e

(b) exposição severa para IDC $>11$.

Nesse caso, seguindo as recomendações de adoção de um nível acima do calculado para áreas distantes até $8 \mathrm{~km}$ do mar ou grandes estuários (MARSH, 1977), as áreas com IDC maior ou igual a $5 \mathrm{~m}^{2} / \mathrm{s}$ e menor que $7 \mathrm{~m}^{2} / \mathrm{s}$ devem ser classificadas como áreas de exposição alta. A Tabela 1 apresenta os níveis de exposição de acordo com as metodologias de Lacy $^{3}$ (apud FAZIO; MALLIDI; ZHU, 1995) e de Chand e Bhargava (2002), e de acordo com as recomendações de elevação de nível para ambos os casos.

Lima e Morelli (2005), adotando a metodologia das quatro faixas de exposição e as recomendações de Marsh (1977), montaram um primeiro mapa de chuva dirigida para o Brasil (Figura 1). Esse mapa ainda é experimental e foi realizado apenas com base nos dados de 2004, disponíveis na página do Centro de Previsão do Tempo e Estudos Climáticos (CPTEC).

Segundo Rydock (2006), os mapas de médias anuais de chuva dirigida podem ser úteis para avaliar o risco de infiltração em fachadas e danos por umidade repetidos em construções ou materiais onde o risco de infiltração é uma função da intensidade da chuva dirigida, além de serem úteis para verificar o umedecimento médio por chuva dirigida de uma parede.

Lacy $^{4}$ (apud FAZIO; MALLIDI; ZHU, 1995) desenvolveu uma relação entre as taxas de deposição de água da chuva em paredes verticais e em superfícies horizontais. Essa relação resultou na Equação 2:

$R_{v}=\frac{2}{9} \cdot V \cdot R_{h}{ }^{8 / 9} \approx 0,222 \cdot V \cdot R_{h}{ }^{0,88}$

Eq. 2

Onde:

$V=$ velocidade do vento $(\mathrm{m} / \mathrm{s})$;

$R_{v}$ e $R_{h}=$ taxa de chuva em superfície vertical e horizontal respectivamente ( $\mathrm{mm} /$ tempo);

$0,222(\mathrm{~s} / \mathrm{m})=$ coeficiente de chuva dirigida (valor médio) resultante de relações empíricas adotadas.

Para se chegar à Equação 2, Lacy ${ }^{5}$ (apud FAZIO; MALLIDI; ZHU, 1995) empregou relações

${ }^{3}$ LACY, R. E. Driving Rain Maps and the Onslaught of Rain on Buildings. In: RILEM/CIB SYMPOSIUM ON MOISTURE PROBLEMS IN BUILDINGS, Helsinki, 1965. Proceedings... Helsinki, 1965.

${ }^{4}$ Idem.

${ }^{5}$ Idem. empíricas que expressam o tamanho médio das gotas como uma função da intensidade da precipitação e a velocidade final de queda das gotas. Para essa equação assume-se que a distribuição do tamanho das gotas na parede é uniforme, com gotas de tamanhos similares, com velocidades finais $\mathrm{V}_{\mathrm{t}}=(1 / 0,222) \mathrm{m} / \mathrm{s}=4,5 \mathrm{~m} / \mathrm{s}$, o que corresponde a um diâmetro de $1,2 \mathrm{~mm}$. O expoente 0,88 pode ser omitido com boa aproximação (BLOCKEN; CARMELIET, 2004).

Rydock et al. (2005), em um estudo sobre a exposição de edificações à chuva dirigida para a Noruega, utilizaram a Equação 3 no cálculo da quantidade acumulada de chuva dirigida em parede vertical, com dados de observações sinóticas.

$I_{0}=0,206 \cdot \sum_{D=\beta-80^{\circ}}^{\beta+80^{\circ}} R_{D} \cdot V_{D} \cdot \cos (D-\beta)$

Eq. 3

Onde:

$I_{o}=$ montante de chuva dirigida em parede vertical (mm/ano);

$V_{D}=$ velocidade anual média do vento para a direção $D(\mathrm{~m} / \mathrm{s})$;

$R_{D}=$ precipitação anual média para a direção $D$ (mm);

$D=$ direção do vento (graus a partir do norte); e

$\beta=$ ângulo entre o $\mathrm{N}$ e a direção normal à parede.

O fator de conversão 0,206 foi determinado por Lacy $^{6}$ (apud RYDOCK et al., 2005) em um estudo de 75 eventos de chuva para um período de 16 anos, no qual $1 \mathrm{~m}^{2} / \mathrm{s}$ ( 1 ICD) corresponde a 0,206 $\mathrm{m}$ ou $206 \mathrm{~mm}$ de chuva dirigida em uma parede vertical (RYDOCK et al., 2005). Em contato por e-mail, o autor principal do artigo justificou o uso do fator 0,206 por Rydock et al. (2005) por ser um fator calculado a partir de um valor médio para uma série de eventos de tempestades (que duram de diversas horas a diversos dias), enquanto o fator 0,222 está relacionado especificamente a dados de vento e totais de chuva horários. Como Rydock et al. (2005) utilizaram nesse estudo dados que continham direções de vento medidas a cada $10^{\circ}$, o cálculo do $\mathrm{I}_{0}$ incluiu um somatório para todas as direções $\mathrm{D}$ que representam vento incidindo na parede incluídos no setor $\beta-80^{\circ}$ a $\beta+80^{\circ}$. Além disso, os autores omitiram o expoente $8 / 9$ do termo $\mathrm{R}_{\mathrm{D}}$, pois, segundo eles, este não se mostrou válido para o cálculo com dados não horários. 
A região de Florianópolis, localizada no litoral catarinense, possui um clima do tipo subtropical úmido. As amplitudes térmicas anuais oscilam entre $8{ }^{\circ} \mathrm{C}$ e $10{ }^{\circ} \mathrm{C}$, e a precipitação é bem distribuída ao longo do ano, com valores médios de $1.500 \mathrm{~mm} / \mathrm{ano}$. Apesar de as chuvas serem bem distribuídas entre as estações do ano, há maior concentração delas no verão (DIAS; HERMANN, 2002).

O clima de Florianópolis é formado pela maritimidade, pelo relevo da Ilha e do continente próximo, pelas massas polares e tropicais, e pelos diversos sistemas, entre eles a frente fria (MONTEIRO; FURTADO, 1995).

Segundo Goulart (1993), os ventos mais frequentes durante todo o ano são os de direção norte, seguidos pelos de direção sul. Os ventos mais fortes (acima de $9 \mathrm{~m} / \mathrm{s}$ ) aparecem em uma frequência maior para a direção sul. Entretanto, segundo Monteiro e Furtado (1995), os ventos mais frequentes em Florianópolis são os de direção nordeste.

Tabela 1 - Faixas de exposição à chuva dirigida com os ajustes sugeridos para áreas distantes até 8 km do mar ou grandes estuários

\begin{tabular}{|c|c|c|c|c|}
\hline \multirow[b]{2}{*}{$\begin{array}{c}\text { Indice de Chuva } \\
\text { Dirigida }\left(\mathrm{m}^{2} / \mathrm{s}\right)\end{array}$} & \multicolumn{4}{|c|}{ Nivel de exposição } \\
\hline & Lacy $^{l}$ & $\begin{array}{l}\text { Chand e } \\
\text { Bhargava }^{2}\end{array}$ & $\begin{array}{c}\text { Lacy }^{1} \text { com } \\
\text { recomendação } o^{3}\end{array}$ & $\begin{array}{c}\text { Chande } \\
\text { Bhargava }^{2} \text { com } \\
\text { recomendação }\end{array}$ \\
\hline $\mathrm{ICD} \leq 3$ & Protegido & Protegido & Moderado & Moderado \\
\hline $3<\mathrm{ICD} \leq 5$ & Moderado & Moderado & Moderado & Moderado \\
\hline $5<\mathrm{ICD} \leq 7$ & Moderado & Moderado & Severo & Alto \\
\hline $7<\mathrm{ICD} \leq 11$ & Severo & Alto & Severo & Severo \\
\hline $\mathrm{ICD}>11$ & Severo & Severo & Severo & Severo \\
\hline
\end{tabular}

Fonte: ${ }^{7}$ Lacy (citado por Fazio, Mallidi e Zhu, 1995), ${ }^{2}$ Chand e Bhargava (2002), ${ }^{3}$ Marsh (1977).

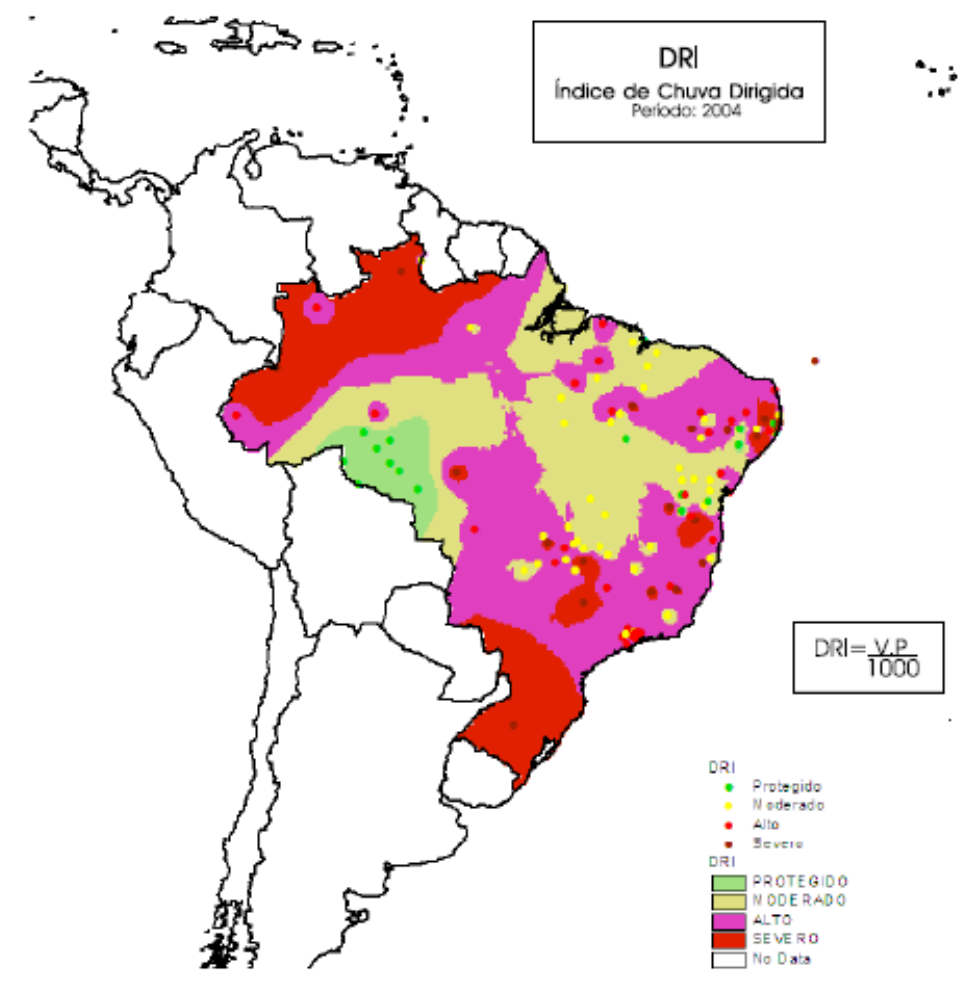

Figura 1 - Mapa brasileiro de chuva dirigida Fonte: Lima e Morelli (2005).

\footnotetext{
${ }^{7}$ LACY, R. E. Driving Rain Maps and the Onslaught of Rain on Buildings. In: RILEM/CIB SYMPOSIUM ON MOISTURE PROBLEMS IN BUILDINGS, Helsinki, 1965. Proceedings... Helsinki, 1965.
} 


\section{Método de pesquisa}

Para fins do presente trabalho, delimitou-se como área de estudo a região do litoral de Florianópolis apresentada pelo Atlas Climatológico Digital do Estado de Santa Catarina (PANDOLFO et al., 2002), abrangida pelas estações meteorológicas cujos dados foram utilizados na avaliação da exposição das edificações à chuva dirigida. A área assim definida é então formada pela cidade de Florianópolis (parte insular e parte continental): a Ilha de Santa Catarina, com exceção de uma pequena porção ao norte, e parte dos municípios de Biguaçu, São José e Palhoça (Figura 2).

Neste estudo foram utilizados dados de direção e velocidade do vento e de precipitação de três estações meteorológicas localizadas na Ilha de Santa Catarina e na cidade vizinha de São José. Três períodos distintos foram analisados:

(a) 1960-1970 (10 anos), com dados da estação do Aeroporto Hercílio Luz armazenados em CD no acervo do LabEEE, anteriormente obtidos pela Associação Brasileira de Refrigeração, Ar Condicionado, Ventilação e Aquecimento/Instituto Brasileiro do Frio (ABRAVA/IBF), junto ao Centro Técnico Aeroespacial/Instituto da Aeronáutica e Espaço (CTA/IAE). Esse CD contém dados horários de vento, sendo a velocidade medida em nós e a direção de 10 em 10 graus, e cinco medidas diárias de precipitação medidas em milímetros. Os ventos foram coletados a uma altura de $12 \mathrm{~m}$;

(b) 1991/1993-1996 (5 anos), com dados horários de vento (velocidade e direção) da estação do Aeroporto Hercílio Luz obtidos pelo National
Climatic Data Center (NCDC) e dados de precipitação em três anotações diárias da Estação São José, obtidos junto à EPAGRI. A velocidade do vento é anotada em décimos de metro por segundo $(0,1 \mathrm{~m} / \mathrm{s})$, a direção é dada em oito direções (N, NE, E, SE, S, SO, O, NO), e a precipitação anotada em milímetros; e

(c) setembro/05-agosto/06 (1 ano), com dados da estação da Barra da Lagoa do Laboratório de Hidráulica Marítima (LaHiMar), aferidos a cada $30 \mathrm{~min}$, sendo a precipitação registrada em polegadas, a velocidade do vento em milhas por hora (mph), e a direção do vento fornecida em 16 direções (N, NNE, NE, ENE, E, ESSE, SE, SSE, $\mathrm{S}$, SSO, SO, OSO, O, ONO, NO, NNO). Os dados de vento foram medidos à altura de $10 \mathrm{~m}$.

Os dados de velocidade do vento de todos os períodos foram transformados em metros por segundo $(\mathrm{m} / \mathrm{s})$, e os dados de direção do vento do primeiro período (1961-1970) foram divididos em oito direções (N, NE, E, SE, S, SO, O, NO), com as direções $\mathrm{N}, \mathrm{E}, \mathrm{S}$ e $\mathrm{O}$ abrangendo 40 graus, e as direções NE, SE, SO e NO abrangendo 50 graus, conforme a Figura 3. Além disso, as anotações de velocidade do vento da estação do Aeroporto Hercílio Luz, (1961-1970 e 1991/1993-1996), foram corrigidas para a altura de $10 \mathrm{~m}$, de acordo com a norma britânica BS 5925 (LIDDAMENT, 1986). A abrangência de cada direção ficou assim definida, pois não foi possível dividir as direções em faixas iguais de 45 graus, dado que os registros na estação foram realizados de 10 em 10 graus. As medidas de precipitação dos períodos de 1961 1970 e de setembro/05-agosto/06 foram convertidas para milímetros (mm).

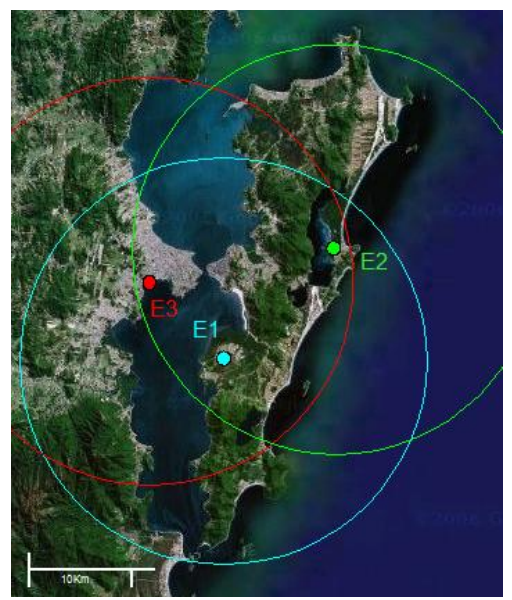

Figura 2 - Localização das estações meteorológicas (E1-Estação Aeroporto Hercílio Luz; E2-Estação Barra da Lagoa - LaHiMar; E3-Estação São José - EPAGRI/INMET) e suas áreas de cobertura (20 km de raio)

Fonte: <http://maps.google.com/, acesso em janeiro/2007>. 


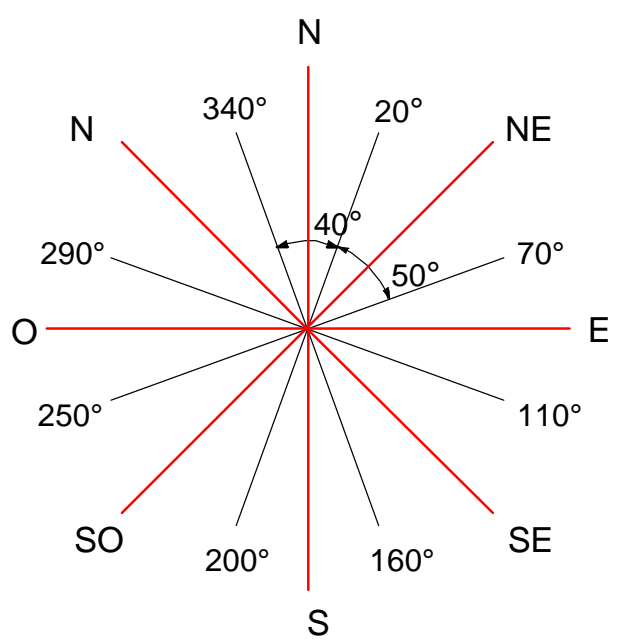

Figura 3 - Transformação das direções de vento medidas em graus para oito direções (N, E, S, 0 abrangendo uma faixa de $40^{\circ}$; NE, SE, SO, NO abrangendo uma faixa de $50^{\circ}$ )

\begin{tabular}{lccc}
\hline \multicolumn{1}{c}{ Período } & ICDa $\left(\mathbf{m}^{2} / \mathbf{s}\right)$ & $\begin{array}{c}\text { Nível de exposição } \\
\text { Chand e Bhargava (2002) }\end{array}$ & $\begin{array}{c}\text { Nível ajustado } \\
\text { Marsh (1977) }\end{array}$ \\
\hline $1961-1970$ & 4,94 & moderado & moderado \\
1991/1993-1996 & 5,40 & moderado & alto \\
set/05-ago/06 & 2,07 & protegido & moderado \\
\hline
\end{tabular}

Tabela 2 - Valores dos ICDa e classificação da exposição à chuva dirigida. Florianópolis, 1961-1970, 1991/1993-1996 e setembro/05-agosto/06

Para possibilitar o cálculo dos índices direcionais de chuva dirigida nos dois primeiros períodos analisados, fez-se a transformação das observações horárias de vento em cinco observações diárias para o primeiro período (1961-1970) e três observações diárias para o segundo período (1991/1993-1996), de acordo com os horários das observações de precipitação pluviométrica. Dessa forma, o valor da velocidade resultante em cada transformação é a média das velocidades horárias entre as observações de precipitação pluviométrica, inclusive a medida do horário da observação, e a direção adotada é a mais frequente (modal) entre essas observações.

Calcularam-se os índices de chuva dirigida para os três períodos, bem como os índices anuais, mensais e sazonais (de acordo com as estações do ano). Foram calculados também os índices direcionais, que, com sua apresentação gráfica em forma de rosetas, facilitam a identificação das direções mais agressivas e, portanto, a indicação das prováveis fachadas mais expostas aos eventos de chuva dirigida. Esses índices foram obtidos aplicando-se a Equação 1 e utilizando-se os dados de vento apenas das observações nas quais houve precipitação. Com os índices anuais e anuais médios fez-se a classificação do nível de exposição à chuva dirigida ao qual as edificações da região de estudo estão submetidas, de acordo com a metodologia de Chand e Bhargava (2002) e considerando as recomendações para áreas próximas ao mar, conforme Marsh (1977).

Foram calculados ainda os montantes de chuva dirigida em parede vertical em cada período para as direções N, NE, E, SE, S, SO, O e NO ( $\mathrm{I}_{360}, \mathrm{I}_{45}$, $\mathrm{I}_{90}, \mathrm{I}_{135}, \mathrm{I}_{180}, \mathrm{I}_{225}, \mathrm{I}_{270}$ e $\mathrm{I}_{315}$ respectivamente) aplicando-se a Equação 3. Esses dados indicam quais fachadas estão mais expostas à chuva dirigida e precisarão de maior atenção dos projetistas.

Os procedimentos descritos acima estão detalhadamente descritos por Giongo (2007).

\section{Resultados}

A Tabela 2 apresenta os ICDa obtidos nos três períodos analisados, a classificação do nível de exposição à chuva dirigida de acordo com a metodologia de Chand e Bhargava (2002), e a classificação ajustada, conforme a recomendação de Marsh (1977), por se tratar de área próxima até $8 \mathrm{~km}$ do mar. 
Pode-se observar uma pequena diferença entre os valores obtidos nos dois primeiros períodos (19611970 e 1991/1993-1996), 4,94 m²/s e $5,40 \mathrm{~m}^{2} / \mathrm{s}$ respectivamente. No entanto, a diferença entre esses e o valor obtido no período setembro/05agosto/06, de $2,07 \mathrm{~m}^{2} / \mathrm{s}$, foi de $58 \%$ e $66 \%$ respectivamente. Assim, o nível de exposição variou de protegido a moderado, conforme a metodologia de Chand e Bhargava (2002). De acordo com as recomendações de Marsh (1977), a exposição nesse período variou de moderada a alta.

$\mathrm{Na}$ análise dos valores dos ICD de cada ano do período 1961-1970 (Tabela 3), observa-se grande variação, sendo o menor valor $3,31 \mathrm{~m}^{2} / \mathrm{s}$ no ano de 1970, e o maior, $7,19 \mathrm{~m}^{2} / \mathrm{s}$ em 1966. De acordo com a metodologia de Chand e Bhargava (2002), o nível de exposição foi moderado para todos os anos do período, exceto para 1966, cuja exposição foi alta $\left(>7 \mathrm{~m}^{2} / \mathrm{s}\right)$. Como se trata de região mais agressiva, a exposição nos anos de 1961, 1967 e 1969 foi considerada alta (> $5 \mathrm{~m}^{2} / \mathrm{s}$ ), e a exposição no ano de 1966, severa. A exposição média no período foi moderada nas duas análises.

O período 1991/1993-1996 apresentou valores de ICD anuais com variações menores que o período 1961-1970 (
Tabela 4). O menor valor obtido é $4,25 \mathrm{~m}^{2} / \mathrm{s}$, em 1993, e o maior, $6,38 \mathrm{~m}^{2} / \mathrm{s}$, em 1995. A exposição foi moderada em todos os anos desse período. No entanto, a exposição nos anos de 1994, 1995 e 1996, assim como a exposição média do período, foi considerada alta devido à proximidade do mar.

A Fehler! Verweisquelle konnte nicht gefunden werden. apresenta os ICD mensais dos três períodos analisados. No período 1961-1970 os maiores valores de ICD mensais foram obtidos para os meses de janeiro a março e setembro a dezembro. Os ICD dos meses de janeiro, fevereiro, março e setembro neste período representam individualmente $11 \%$ do valor do ICDa. No período 1991/1993-1996 os maiores ICD mensais foram obtidos nos meses de janeiro a março, novembro e dezembro, e os meses de dezembro e fevereiro representaram $16 \%$ e $14 \%$ do ICDa respectivamente, janeiro, $12 \%$, e novembro e fevereiro, $11 \%$. No período setembro/05agosto/06, os maiores valores ocorreram nos meses de janeiro a março e setembro a dezembro, sendo o maior valor obtido em setembro, de $0,52 \mathrm{~m}^{2} / \mathrm{s}$ representando $25 \%$ do valor do ICDa do período.

Tabela 3 - Valores dos ICDa para o período 1961-1970 e classificação da exposição à chuva dirigida (Florianópolis, Aeroporto Hercílio Luz)

\begin{tabular}{cccl}
\hline Ano & ICDa $\left(\mathbf{m}^{2} / \mathbf{s}\right)$ & $\begin{array}{c}\text { Nível de exposição } \\
\text { Chand e Bhargava (2002) }\end{array}$ & $\begin{array}{c}\text { Nível ajustado } \\
\text { Marsh (1977) }\end{array}$ \\
\hline 1961 & 6,45 & moderado & alto \\
1962 & 4,18 & moderado & moderado \\
1963 & 3,95 & moderado & moderado \\
1964 & 3,68 & moderado & moderado \\
1965 & 4,99 & moderado & moderado \\
1966 & 7,19 & alto & severo \\
1967 & 5,71 & moderado & alto \\
1968 & 3,85 & moderado & moderado \\
1969 & 6,25 & moderado & alto \\
1970 & 3,31 & moderado & moderado \\
Média & 4,96 & moderado & moderado \\
\hline ICDa médio & $\mathbf{4 , 9 4}$ & moderado & moderado \\
calculado & & & \\
\hline
\end{tabular}


Tabela 4 - Valores dos ICDa para os anos de 1991, 1993-1996 e classificação da exposição à chuva dirigida

\begin{tabular}{cccc}
\hline Ano & ICDa $\left(\mathbf{m}^{2} / \mathbf{s}\right)$ & $\begin{array}{c}\text { Nível de exposição } \\
\text { Chand e Bhargava (2002) }\end{array}$ & $\begin{array}{c}\text { Recomendação } \\
\text { BRS Digest }\end{array}$ \\
\hline 1991 & 4,88 & moderado & moderado \\
1993 & 4,25 & moderado & moderado \\
1994 & 5,67 & moderado & alto \\
1995 & 6,38 & moderado & alto \\
1996 & 5,86 & moderado & alto \\
Média & 5,41 & moderado & alto \\
\hline ICDa médio & $\mathbf{5 , 4 0}$ & moderado & alto \\
calculado & &
\end{tabular}

Tabela 5 - Índices de chuva dirigida mensais e índice de chuva dirigida anual $\left(\mathrm{m}^{2} / \mathrm{s}\right)$, Florianópolis, 1961-1970, 1991/1993-1996 e setembro/05-agosto/06

\begin{tabular}{cccc}
\hline & \multicolumn{3}{c}{ ICDmensal médio $\left(\mathbf{m}^{2} / \mathbf{s}\right)$} \\
\cline { 2 - 4 } & $\mathbf{1 9 6 1 - 1 9 7 0}$ & $\mathbf{1 9 9 1 / 1 9 9 3 - 1 9 9 6}$ & set/05-ago/06 \\
\hline Janeiro & 0,55 & 0,66 & 0,25 \\
Fevereiro & 0,54 & 0,74 & 0,14 \\
Março & 0,52 & 0,57 & 0,26 \\
Abril & 0,28 & 0,17 & 0,03 \\
Maio & 0,27 & 0,35 & 0,09 \\
Junho & 0,32 & 0,31 & 0,03 \\
Julho & 0,30 & 0,25 & 0,04 \\
Agosto & 0,29 & 0,14 & 0,11 \\
Setembro & 0,52 & 0,38 & 0,52 \\
Outubro & 0,47 & 0,37 & 0,19 \\
Novembro & 0,43 & 0,60 & 0,18 \\
Dezembro & 0,43 & 0,86 & 0,19 \\
Soma & 4,92 & 5,40 & 2,03 \\
\hline ICDa & 4,94 & 5,40 & 2,07 \\
\hline
\end{tabular}

Tabela 6 - Índices de chuva dirigida sazonais e índice de chuva dirigida anual $\left(\mathrm{m}^{2} / \mathrm{s}\right)$, Florianópolis, 1961-1970, 1991/1993-1996 e setembro/05-agosto/06

\begin{tabular}{cccc}
\hline & \multicolumn{3}{c}{ ICDsazonal médio $\left(\mathbf{m}^{2} / \mathbf{s}\right)$} \\
\cline { 2 - 4 } & $\mathbf{1 9 6 1 - 1 9 7 0}$ & $\mathbf{1 9 9 1 / 1 9 9 3 - 1 9 9 6}$ & set/05-ago/06 \\
\hline Primavera & 1,43 & 1,34 & 0,88 \\
Verão & 1,52 & 2,27 & 0,58 \\
Outono & 1,06 & 1,09 & 0,40 \\
Inverno & 0,91 & 0,70 & 0,18 \\
Soma & 4,92 & 5,40 & 2,04 \\
\hline ICDa & 4,94 & 5,40 & 2,07 \\
\hline
\end{tabular}

Pela análise dos ICD sazonais (estações do ano) (Tabela 6), observa-se que os maiores índices foram obtidos na primavera e no verão em todos os períodos analisados. O inverno é a estação com os menores índices nos três períodos. No período 1961-1970, a diferença entre os ICD da primavera e do verão é pouco significativa, representando $29 \%$ e $31 \%$ do ICDa do período respectivamente.
Já no período 1991/1993-1996 o verão apresentou o maior ICD, com valor de $2,26 \mathrm{~m}^{2} / \mathrm{s}$, que representa $42 \%$ do ICDa desse período, e a primavera apresentou o segundo maior ICD, com valor de $1,35 \mathrm{~m}^{2} / \mathrm{s}$, que representa $25 \%$ do ICDa. O período setembro/05-agosto/06 apresentou o maior índice na primavera, $0,88 \mathrm{~m}^{2} / \mathrm{s}$, representando $43 \%$ do ICDa do período, e o segundo maior índice no 
verão, $0,58 \mathrm{~m}^{2} / \mathrm{s}$, representando $28 \%$ do ICDa. Esse resultado, em que a primavera apresenta maior índice que o verão, contrariando a tendência dos períodos anteriores, pode ser atribuído à contribuição do mês de setembro, que teve o maior ICD mensal desse período.

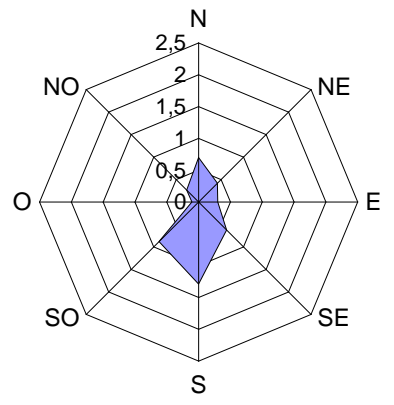

ICDd 1961-1970

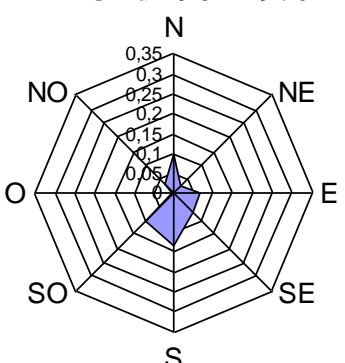

Fevereiro

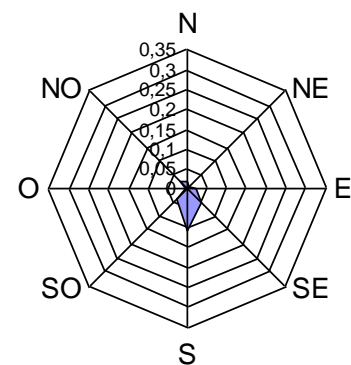

Abril

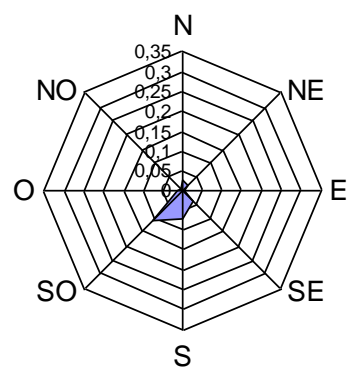

Julho

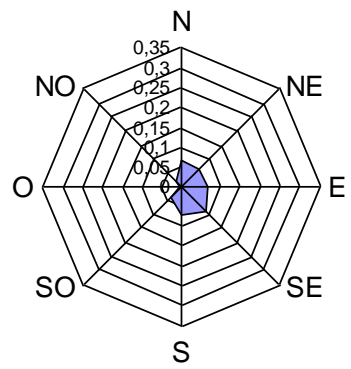

Outubro
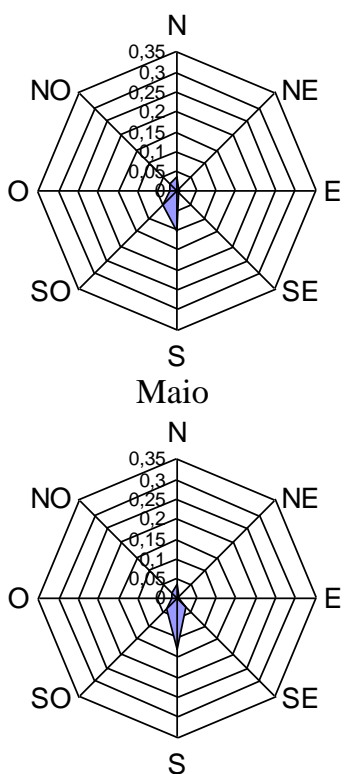

Agosto

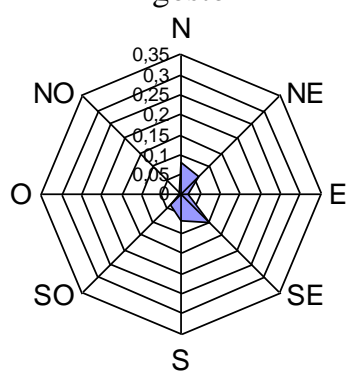

Novembro

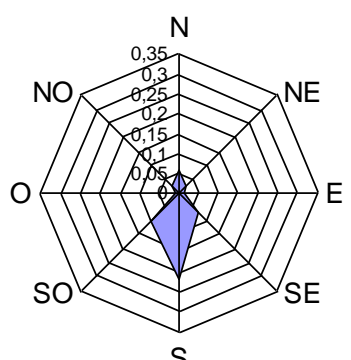

Março

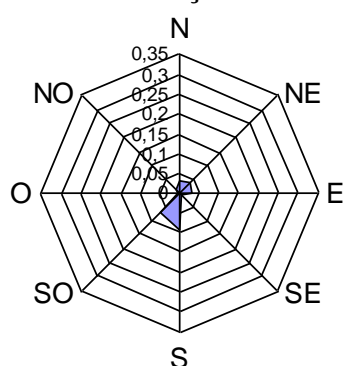

Junho

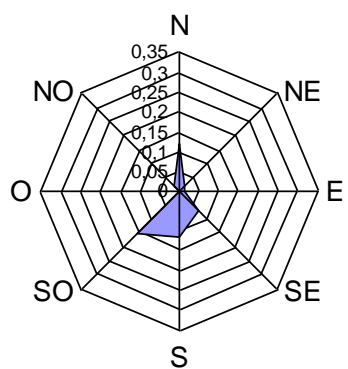

Setembro

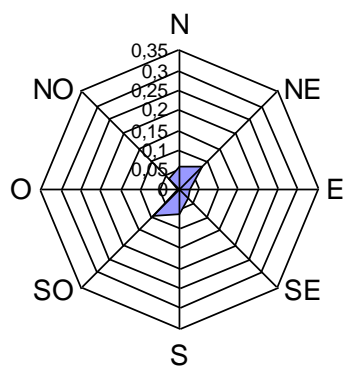

Dezembro

Figura 4 - Índice de chuva dirigida direcional anual e índices de chuva dirigida direcionais mensais $\left(\mathrm{m}^{2} / \mathrm{s}\right)$, Florianópolis 1961-1970 


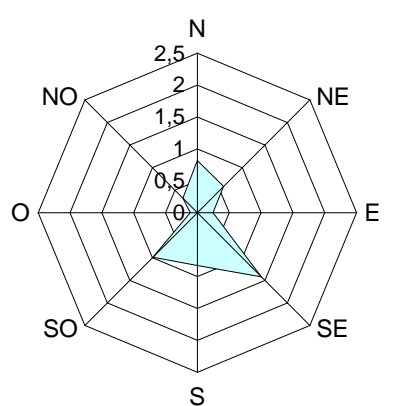

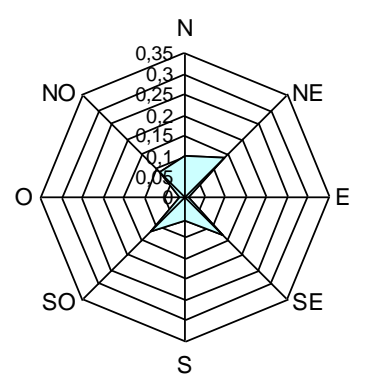

Janeiro

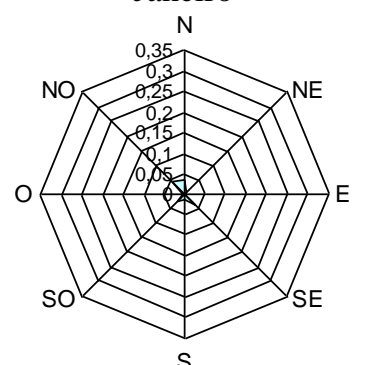

Abril

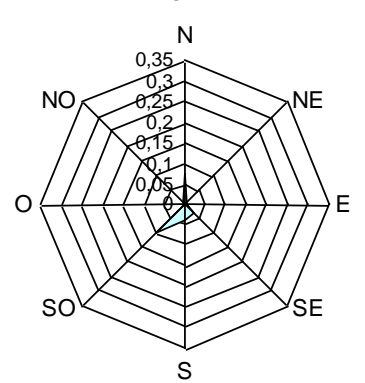

Julho

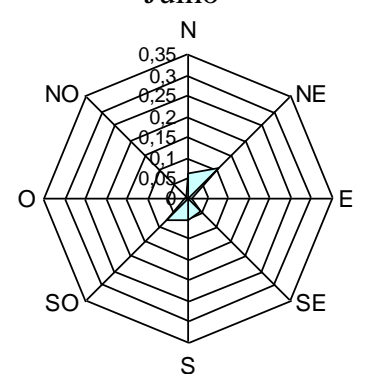

Outubro

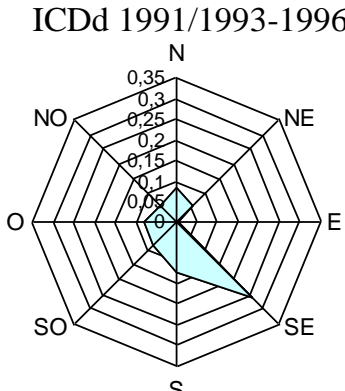

Fevereiro

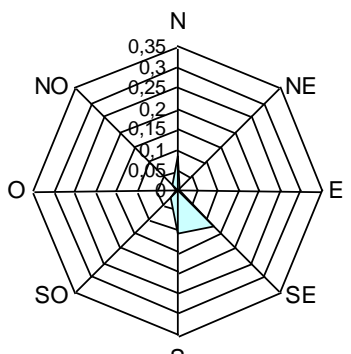

Maio

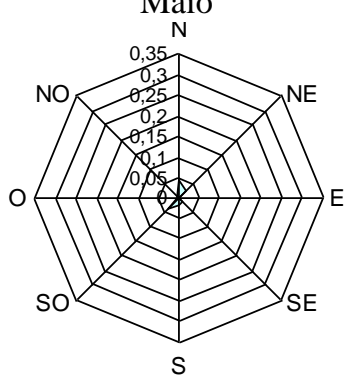

Agosto

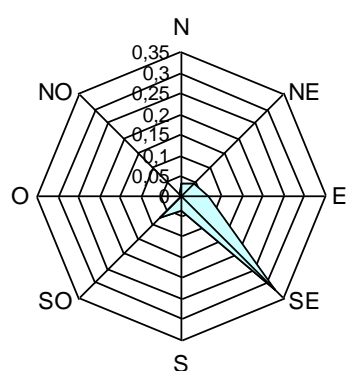

Novembro
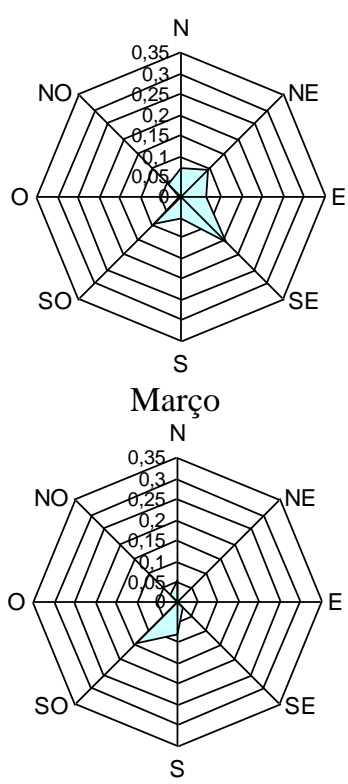

Junho

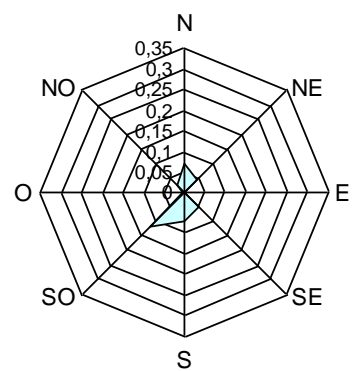

Setembro

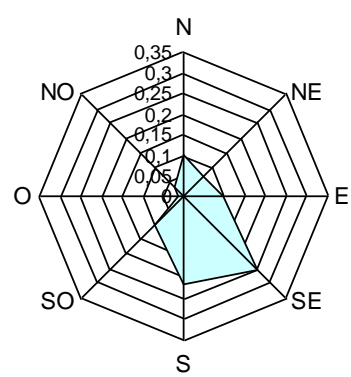

Dezembro

Figura 5 - Índice de chuva dirigida direcional anual e índices de chuva dirigida direcionais mensais $\left(\mathrm{m}^{2} / \mathrm{s}\right)$, Florianópolis 1991/1993-1996 
As rosetas com os ICDd e ICDd mensais do período 1961-1970 podem ser vistas na Figura 4. Observa-se, na roseta de ICDd, que as direções mais críticas nesse período são $\mathrm{S}, \mathrm{SO}, \mathrm{SE}$ e N, com o maior ICDd na direção $\mathrm{S}$, com valor de 1,29 $\mathrm{m}^{2} / \mathrm{s}$, representando $26 \%$ do ICDa do período. A direção $\mathrm{O}$ aparece como a menor contribuinte para o ICDa, com ICDd de $0,11 \mathrm{~m}^{2} / \mathrm{s}$.

Observando-se as rosetas de ICDd mensais do período 1961-1970, vê-se que, de forma geral, o quadrante sul é o mais crítico quanto à exposição à chuva dirigida. A direção $\mathrm{S}$ foi a mais agressiva em 7 meses do ano, sendo alguns deles os meses com os maiores índices de chuva dirigida (ver Tabela 5). O maior ICDd mensal ocorreu em março, com um valor de $0,22 \mathrm{~m}^{2} / \mathrm{s}$ na direção $\mathrm{S}$.

A Figura 5 apresenta as rosetas com os ICDd e ICDd mensais do período 1991/1993-1996. A roseta de ICDd indica que a direção mais crítica é a SE, com um ICDd igual a $1,42 \mathrm{~m}^{2} / \mathrm{s}$, representando $26 \%$ do ICDa do período. A segunda direção mais agressiva é a SO, com um ICDd igual a $1,00 \mathrm{~m}^{2} / \mathrm{s}$. As direções $\mathrm{N}$ e $\mathrm{S}$ apresentaram ICDd sem diferença significativa, $0,82 \mathrm{~m}^{2} / \mathrm{s}$ e $0,83 \mathrm{~m}^{2} / \mathrm{s}$ respectivamente. É interessante observar que as direções do quadrante sul, S, SO e SE, representam juntas $60 \%$ do ICDa médio. Assim como no período 1961-1970, a direção $\mathrm{O}$ foi a menos crítica do período.

$\mathrm{Na}$ Figura 5, observa-se que, nos meses com os maiores ICD mensais, a direção mais crítica foi a $\mathrm{SE}$, exceto no mês de janeiro. Nesse mês, as direções do quadrante norte tiveram mais ou menos a mesma intensidade de chuva dirigida que as direções do quadrante sul. Em dezembro, que foi em média o mês mais agressivo do período, as direções que apresentaram os maiores ICDd foram a $\mathrm{SE}$ e a $\mathrm{S}$, sendo elas responsáveis por $54 \%$ do ICD mensal médio.

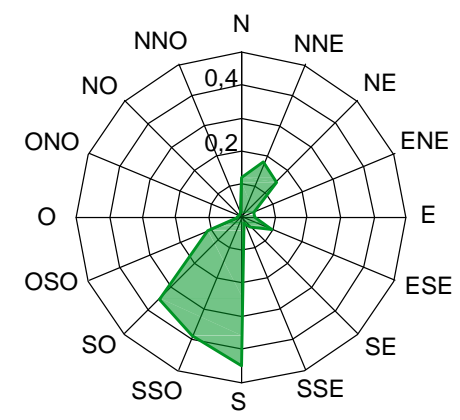

ICDa setembro/05-agosto/06

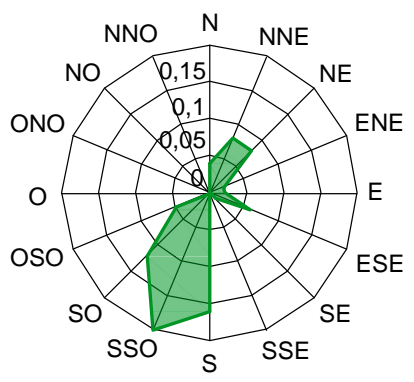

Primavera

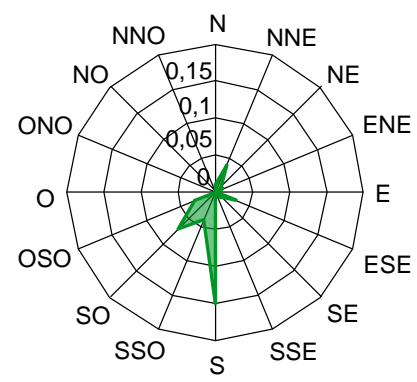

Outono
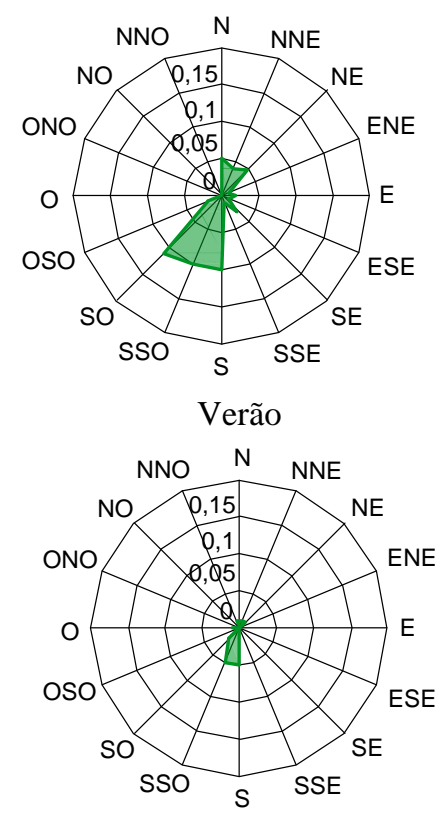

Inverno

Figura 6 - Índice de chuva dirigida direcional anual e índices de chuva dirigida direcionais sazonais $\left(\mathrm{m}^{2} / \mathrm{s}\right)$, Florianópolis setembro/05-agosto/06 
As rosetas de ICDd anual e ICDd sazonais do período setembro/05-agosto/06 estão divididas em 16 direções, pois os dados disponíveis para esse período foram fornecidos em 16 direções (Figura 6). Apesar do ICDa reduzido em relação aos ICDa dos períodos anteriores, as direções do quadrante sul (S, SSO e SO) foram as mais agressivas, representando juntas $57 \%$ do ICDa desse período. Essas mesmas direções também foram as mais críticas em todas as estações do ano. Na primavera,

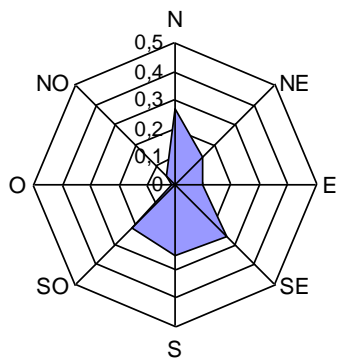

Primavera

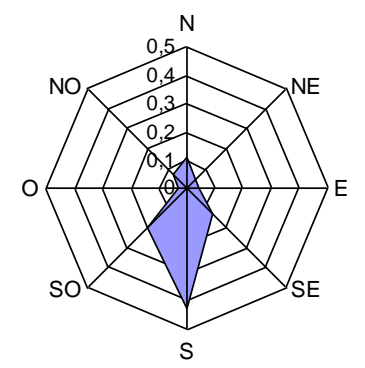

Outono a estação com maior ICD sazonal, a direção mais agressiva foi a SSO, com um ICDd de $0,20 \mathrm{~m}^{2} / \mathrm{s}$.

A Figura 7 apresenta os ICDd sazonais do período 1961-1970. No outono e no inverno a direção $S$ foi a mais agressiva. $\mathrm{Na}$ primavera, a direção $\mathrm{N}$ apresenta um ICDd igual às direções S e SE. Neste período, o verão foi a estação com o maior ICD sazonal e, apesar da melhor distribuição da chuva dirigida entre as oito direções de vento, o quadrante sul foi o mais crítico.

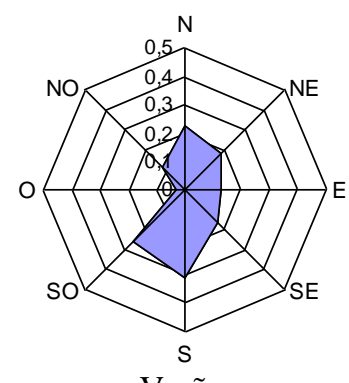

Verão

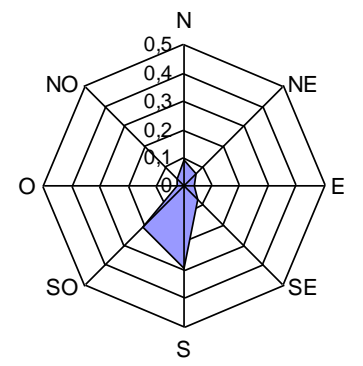

Inverno

Figura 7 - Índices de chuva dirigida direcionais sazonais (m²/s), Florianópolis 1961-1970

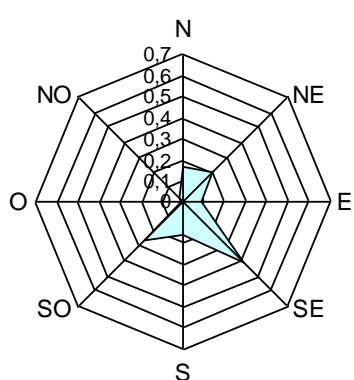

Primavera

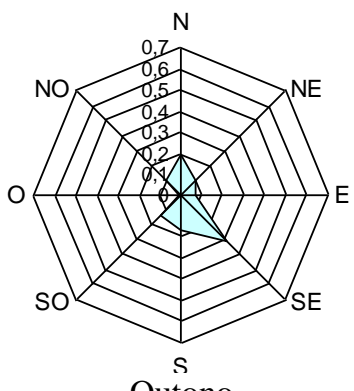

Outono

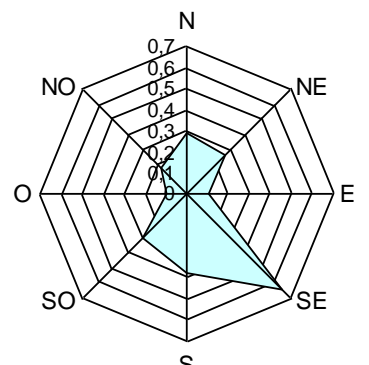

Verão

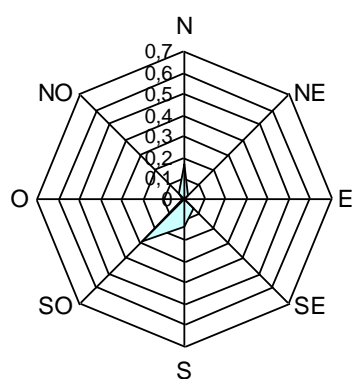

Inverno

Figura 8 - Índices de chuva dirigida direcionais sazonais (m²/s), Florianópolis 1991/1993-1996 
As rosetas de ICDd sazonais do período 1991/1993-1996 podem ser vistas na Figura 8. Em todas as estações do ano desse período o quadrante sul foi o mais crítico. O verão foi a estação mais agressiva, na qual a direção SE aparece claramente como a mais crítica, com um ICDd igual a 0,65 $\mathrm{m}^{2} / \mathrm{s}$, representando $29 \%$ do índice sazonal de verão. Na primavera, as direções mais agressivas foram a $\mathrm{SO}$ e a $\mathrm{SE}$; no outono, a SE; e no inverno, a SO.

A Figura 9 apresenta os valores dos índices de chuva dirigida em parede vertical $\left(\mathrm{I}_{0}\right)$ dos três períodos analisados para oito orientações de fachadas. Observa-se que no período 1991/19931996, o período com o maior ICDa médio, as fachadas mais críticas são a $\mathrm{S}$ e a $\mathrm{SE}$, com $\mathrm{I}_{0}$ iguais a $522 \mathrm{~mm} / \mathrm{ano}$ e $449 \mathrm{~mm} / \mathrm{ano}$ respectivamente. No período 1961-1970, a fachada mais agressiva foi a $\mathrm{S}$, com $\mathrm{I}_{0}$ igual a $484 \mathrm{~mm} / \mathrm{ano}$. No período setembro/05-agosto/06, as fachadas mais expostas foram a $\mathrm{S}$ e a $\mathrm{SO}$, com $\mathrm{I}_{0}$ iguais a $244 \mathrm{~mm} / \mathrm{ano}$ e $236 \mathrm{~mm} / \mathrm{ano}$ respectivamente. Em todos os períodos analisados a direção menos crítica foi a NO.

\section{Discussão}

O mapa brasileiro de chuva dirigida (LIMA; MORELLI, 2005) indica nível de exposição alto para Florianópolis, que corresponde a ICDa maior ou igual a $7 \mathrm{~m}^{2} / \mathrm{s}$, de acordo com a metodologia adotada. No presente trabalho, os ICDa calculados foram iguais a 4,94 m²/s (1961-1970), 5,40 m²/s (1991/1993-1996) e 2,07 m²/s (set/05-ago/06). Nota-se que o valor obtido no terceiro período analisado é muito inferior aos obtidos nos outros períodos, o que leva a concluir que se trata, muito provavelmente, de um ano atípico. O mesmo se pode concluir do ano de 2004, cujos dados foram utilizados na montagem do mapa brasileiro de chuva dirigida, uma vez que o IDCa difere, no mínimo, em 22,8\% e em 1 nível de exposição acima. Além disso, Silva e Giralt (1995) calcularam o ICDa para Porto Alegre com dados de 4 anos e encontraram valor de $3,92 \mathrm{~m}^{2} / \mathrm{s}$, exposição moderada, enquanto o mapa brasileiro indica exposição severa. Isso reforça a teoria de que o ano de 2004 é atípico.

É importante notar que as avaliações climáticas devem ser feitas preferencialmente com séries históricas de no mínimo cinco anos, sendo mais recomendado que se utilizem 10 a 30 anos, pois a análise de menos de 5 anos apenas pode subestimar ou superestimar o nível real de exposição de determinado lugar. A variabilidade dos ICDa obtidos neste estudo e o mapa brasileiro de chuva dirigida confirmam isso.

Além da possibilidade de ano atípico, a grande diferença entre os ICDa dos dois primeiros períodos analisados e o ICDa do terceiro período pode ter sido causada por outros fatores. Entre esses, o mais provável é a interferência do entorno da estação do LaHiMar, uma vez que está localizada sobre uma edificação de dois andares com outras edificações na proximidade, além de vegetação, diferente da estação do Aeroporto Hercílio Luz, que está num espaço mais aberto e mais exposto ao vento. É necessária a análise de série histórica dessa estação e das outras para um mesmo período, de forma a obter resultados mais conclusivos.

A avaliação dos ICDd médio, mensais e sazonais indicou a maior agressividade das direções do quadrante sul. Os resultados dos índices em parede vertical confirmaram que a fachada com orientação sul é a mais exposta em Florianópolis. Esse resultado pode ter relação com os fortes ventos com essa direção (GOULART, 1993), embora os ventos mais frequentes sejam os de direções $\mathrm{N}$ e NE (GOULART, 1993; MONTEIRO; FURTADO, 1995).

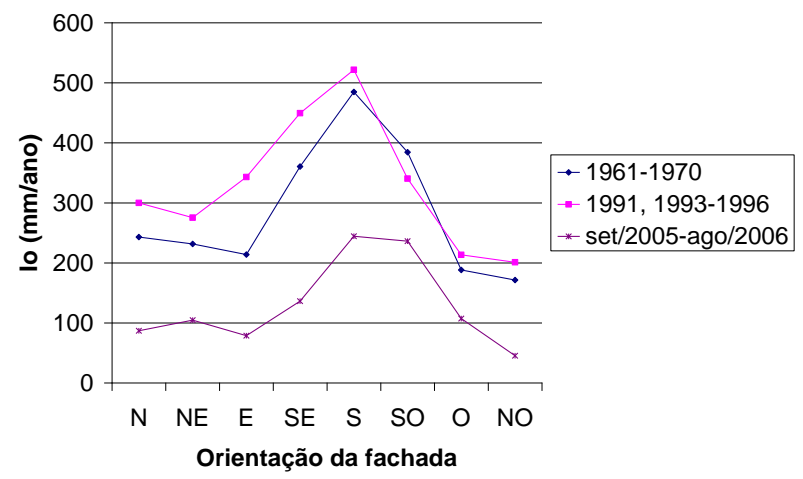

Figura 9 - Índices de chuva dirigida em parede vertical (mm/ano), Florianópolis 1961-1970, 1991/19931996 e setembro/05-agosto/06 
Ainda que a análise da chuva dirigida feita por médias, como é o caso dos ICD, não possa ser utilizada como parâmetro para a avaliação de estanqueidade das fachadas e seus componentes, uma vez que as médias mascaram o valor máximo crítico, seu conhecimento é útil para estudos de durabilidade.

\section{Conclusões e considerações finais}

Durante a realização deste trabalho, constatou-se dificuldade na obtenção de dados para o estudo sobre a chuva dirigida no Brasil, sendo esse um dos motivos para poucas publicações sobre o assunto. A disponibilização de séries históricas junto aos órgãos de meteorologia em nosso país é bastante burocrática e, geralmente, só é feita com dados médios diários. Sabe-se que, quanto menor for o intervalo entre as medições, mais precisos serão os resultados obtidos. Além disso, para uma análise que possibilitasse o estudo da agressividade da chuva dirigida quanto à estanqueidade das fachadas, seriam necessários dados da duração dos eventos de chuva, além dos dados de vento e de precipitação desses eventos.

No presente trabalho, foram utilizados dados sinóticos com diferentes intervalos de medição dos dados de precipitação pluviométrica e com dados horários de vento em dois períodos analisados. Para a análise desses dados, apresentou-se uma metodologia de uniformização dos dados de vento (velocidade e direção), de forma que, para cada medida de precipitação, houvesse uma medida uniformizada de direção e velocidade do vento. É necessário que se façam novas análises, no entanto essa metodologia deu boas indicações de aplicabilidade, uma vez que os dois primeiros períodos avaliados apresentaram resultados aproximados, mesmo com diferentes intervalos de medição da precipitação, além de essas medições serem realizadas em estações meteorológicas diferentes.

No que tange ao estudo de durabilidade de fachadas e componentes de edificações, os índices de chuva dirigida e os índices de chuva dirigida em parede vertical são informações bastante úteis. Uma vez conhecidas as necessidades das edificações de um lugar, as estratégias adotadas nele podem ser aplicadas em outro lugar cujos índices de chuva dirigida sejam aproximadamente iguais.

Para a análise e estudo de manifestações patológicas em fachadas, a apresentação gráfica em forma de rosetas dos índices de chuva dirigida facilita a identificação das orientações de fachadas que têm maior possibilidade de enfrentar problemas e que, dessa forma, necessitam de maior atenção em sua manutenção e no momento do projeto.

Identificou-se que, para Florianópolis, as fachadas voltadas para o quadrante sul são as mais expostas à chuva dirigida. A situação dessas fachadas se agrava ainda mais pelo fato de que, devido à latitude da área, elas receberão pouca ou nenhuma insolação no inverno, facilitando a formação de bolores e o manchamento delas.

Por fim, constatou-se a necessidade de revisão da exposição de Florianópolis indicada no mapa brasileiro de chuva dirigida, que difere significativamente dos resultados obtidos no presente trabalho. Sugere-se a revisão do mapa utilizando uma série maior de anos, uma vez que existe a possibilidade de o ano de 2004, cujos dados foram utilizados na montagem do mapa, ser um ano atípico.

\section{Referências}

ASSOCIAÇÃO BRASILEIRA DE NORMAS

TÉCNICAS. NBR 15575-4: desempenho de edifícios habitacionais de até 5 pavimentos: desempenho: parte 4: sistemas de vedações verticais externas e internas. Rio de Janeiro, 2009. $51 \mathrm{p}$.

BLOCKEN, B.; CARMELIET, J. A Review of Wind-driven Rain Research in Building Science. Journal of Wind Engineering and Industrial Aerodynamics, v. 92, n. 13, p. 1079-1130, Nov. 2004.

BLOCKEN, B.; HENS, H.; CARMELIET, J.

Methods for the Quantification of Driving Rain on Buildings. ASHRAE Transactions, v. 108, n. 2, p. 338-350, 2002.

BRITISH STANDARDS INSTITUTE. BS 5262: code of practice for external rendered finishes. London: BSI, 1976. 21p.

CHAND, I.; BHARGAVA, P. K. Estimation of Driving Rain Index for India. Building and Environment, v. 37, n. 5, p. 549-554, maio. 2002.

CHOI, E. C. C. Wind-Driven Rain on Building Faces and The Driving-Rain Index. Journal of Wind Engineering and Industrial

Aerodynamics, v. 79, n. 1/2, p.105-122, jan. 1999.

CONSTRUCTION INDUSTRY RESEARCH AND INFORMATION ASSOCIATION (CIRIA). Wall Technology: performance requirements. London: CIRIA, 1992. v. A. 
DIAS, F. P.; HERRMANN, M. L. de P.

Susceptibilidade a Deslizamentos: estudo de caso no bairro Saco Grande, Florianópolis, SC.

Caminhos de Geografia, v. 3, n. 6, p. 57-73, jun 2002.

FAZIO, P.; MALLIDI, S. R.; ZHU, D. A Quantitative Study for the Measurement of Driving Rain Exposure in the Montreal Region. Building and Environment, v. 30, n. 1, p. 1-11, jan. 1995.

GIONGO, M. Análise do Nível de Exposição das Edificações à Chuva Dirigida para

Florianópolis. 2007. 107 f. Dissertação (Mestrado em Engenharia Civil) - Programa de PósGraduação em Engenharia Civil, Universidade Federal de Santa Catarina, Florianópolis, 2007.

GOULART, S. G. V. Dados Climáticos para Avaliação de Desempenho Térmico de Edificações em Florianópolis. 1993. 111 f. Dissertação (Mestrado em Engenharia Civil) Programa de Pós-Graduação em Engenharia Civil, Universidade Federal de Santa Catarina, Florianópolis, 1993.

IOSHIMOTO, E. Incidência de Manifestações Patológicas em Edificações Habitacionais. In: EPUSP: série A, pt. 5, São Paulo, 1988. p. 361378.

KARAGIOZIS, A.; HADJISOPHOCLEOUS, G.; CAO, S. Wind-Driven Rain Distributions on Two Buildings. Journal of Wind Engineering and Industrial Aerodynamics, v. 67/68, p. 559-572, abr./jun. 1997.

LACY, R. E. Climate and Building in Britain: Building Research Establishment. London: Her Majesty's Stationery Office, 1977. 185 p.

LACY, R. E. Survey of Meteorological Information for Rrchitecture and Building. (S.l): Building Research Station, Departamento of the Environment, 22 p., 1972.

LACY, R. E.; SHELLARD, H. C. An Index of Driving Rain. Meteorological Magazine, v. 91, n. 1080, p. 177-184, 1962.

LIDDAMENT, M. W. Air infiltration

Calculation Techniques: an applications guide: catálogo de produtos. Great Britain: AIVC, 1986.

LIMA, M. G.; MORELLI, F. Mapa Brasileiro de "Chuva Dirigida": algumas considerações. Florianópolis, SC. 2005. In: SIMPÓSIO BRASILEIRO DE TECNOLOGIA DE ARGAMASSA, 6., Florianópolis, 2005; INTERNATIONAL SYMPOSIOUM ON MORTARS TECHNOLOGY, 1., Florianópolis, 2005. Anais... Florianópolis, 2005.
MARSH, P. Air and Rain Penetration of Buildings. London: The Constrution Press, 1977.

MONTEIRO, M. A.; FURTADO, S. O Clima do Trecho Florianópolis - Porto Alegre: uma abordagem dinâmica. Geosul: Revista do Departamento de Geociências da UFSC, Florianópolis, v. 10, n. 19/20, p. 117-133, 1995.

MUSTELIER, N. L. Avaliação do Desempenho de Blocos e Argamassas com Cinza Pesada de Carvão Mineral Incorporados para Seu Aproveitamento nos Conjuntos Habitacionais. 2002. 100 f. Dissertação (Mestrado em Engenharia Civil) - Programa de Pós-Graduação em Engenharia Civil, Universidade Federal de Santa Catarina, 2002.

PANDOLFO, C. et al. Atlas Climatológico Digital do Estado de Santa Catarina. Florianópolis: Epagri, 2002. 1 CD-ROM.

PEREZ, A. R. Umidade nas Edificações: recomendações para a prevenção da penetração de água pelas fachadas. In: Tecnologia de Edificações: $1^{\text {a }}$ parte. São Paulo: PINI, IPTDivisão de Edificações, 1988. p. 571-574.

RYDOCK, J. P. A Look at Driving Rain Intensities at Five Cities. Building and Environment, v. 41, n. 12, p. 1860-1866, 2006.

RYDOCK, J. P. et al. A Driving Rain Exposure Index for Norway. Building and Environment, v. 40, n. 11, p. 1450-1458, nov. 2005.

SABBATINI, F. H. Umidade por Infiltração em Paredes de Alvenaria. In: EPUSP: série A, pt. 5. São Paulo, 1988. p. 95-104.

SILVA, A. C. S. B.; GIRALT, R. P. Estabelecimento de um Índice de Chuva Dirigida para Porto Alegre. In: ENCONTRO NACIONAL DE TECNOLOGIA DO AMBIENTE CONSTRUÍDO, 95., Rio de Janeiro, 1995. Anais... Rio de Janeiro: ANTAC, 1995.

STRAUBE, J. F.; BURNETT, E. F. P. Driving Rain on Building Façades. In: CLIMA 2000, Bruxelas. Anais... Bruxelas, 1997.

VAN MOOK, F. J. R. Driving Rain on Building Envelopes. 2002. 198 f. Thesis (Ph.D. Thesis) Technische Universiteit Eindhoven, Netherlands, 2002.

\section{Agradecimentos}

Agradecemos à Empresa de Pesquisa Agropecuária e Extensão Rural de Santa Catarina (Epagri), por nos ter fornecido os dados da estação de São José, e ao Laboratório de Hidráulica Marítima (LaHiMar), pelo fornecimento dos dados da estação da Barra da Lagoa. 
Revista Ambiente Construído

Associação Nacional de Tecnologia do Ambiente Construído

Av. Osvaldo Aranha, $99-3^{\circ}$ andar, Centro

Porto Alegre - RS - Brasil

CEP 90035-190

Telefone: +55 (51) 3308-4084

Fax: +55 (51) 3308-4054

www.seer.ufrgs.br/ambienteconstruido

E-mail: ambienteconstruido@ufrgs.br 